\title{
Morphology Result Standard Unit
}

National Cancer Institute

\section{Source}

National Cancer Institute. Morphology Result Standard Unit. NCI Thesaurus. Code

C117615.

The standard unit of measure for morphology results. 